\title{
Os condicionantes institucionais e sociais do recrutamento da elite política do cooperativismo agroindustrial ${ }^{1}$
}

\author{
The institutional and social conditioning of recruitment of the \\ agroindustrial cooperativism political elite \\ Paulo Roberto Neves Costa ${ }^{1}$ (D) Paulo Roberto Stöberl² (1) \\ 1Programa de Pós-graduação em Ciência Política, Universidade Federal do Paraná (UFPR), Curitiba (PR), Brasil. E-mail: \\ paulocostaufpr@gmail.com \\ ${ }^{2}$ Programa de Pós-graduação em Gestão de Cooperativas, Escola de Negócios, Pontíficia Universidade Católica do Paraná \\ (PUCPR), Curitiba (PR), Brasil. E-mail: paulo.stoberl@pucpr.br
}

\begin{abstract}
Como citar: Costa, P. R. N., \& Stöberl, P. R. (2022). Os condicionantes institucionais e sociais do recrutamento da elite política do cooperativismo agroindustrial. Revista de Economia e Sociologia Rural, 60(3), e232252.
\end{abstract}

https://doi.org/10.1590/1806-9479.2021.232252

\begin{abstract}
Resumo: Este artigo analisa o processo de recrutamento dos dirigentes da entidade de representação política do cooperativismo empresarial, os quais compõem o que chamamos de elite cooperativista. O objeto é o Sindicato e Organização das Cooperativas do Estado do Paraná (OCEPAR) nas duas últimas décadas. A pesquisa considerou, de um lado, os condicionantes institucionais, externos e internos a esta entidade e, de outro, os aspectos sociais dos membros desta elite. Além da produção de categorias analíticas que deem conta das particularidades desta elite, foram utilizados a legislação brasileira relativa ao cooperativismo, dados econômicos, documentos da OCEPAR e de outras entidades do cooperativismo e entrevistas. Constatamos que os aspectos institucionais do cooperativismo empresarial e as características sociais dos dirigentes desta entidade ajudam a explicar o fato de os presidentes das maiores cooperativas agroindustriais ocuparem de forma majoritária a diretoria da OCEPAR e, assim, se constituírem enquanto um canal de poder político entre tais cooperativas e a entidade, e desta com as autoridades e instituições políticas. Portanto, verificamos que alguns aspectos institucionais e sociais impactam fortemente 0 recrutamento desta elite cooperativista e, assim, a constituição do cooperativismo agroindustrial enquanto ator político, dimensão de grande relevância para tratarmos da sua importância econômica.
\end{abstract}

Palavras-chave: cooperativismo, cooperativas empresariais, cooperativas agroindustriais, elite cooperativista, Paraná, OCEPAR.

\begin{abstract}
This article analyses the recruitment process of the leaders of the political representative entity of business cooperativism, which compose what we call the cooperative elite. The object is the Union and Organization of Cooperatives of Paraná State (OCEPAR) in the last two decades. The research considered, on one hand, the institutional constraints, external and internal to this entity, and, on the other hand, the social aspects of the members of this elite. In addition to the production of analytical categories able to deal with the particularities of this elite, we used Brazilian legislation on cooperatives, some economic data, documents from OCEPAR and other cooperative entities, and interviews. We found that the institutional aspects of business cooperativism and the social characteristics of this entity's leaders help to explain why presidents of the largest agro-industrial cooperatives occupy the majority of the OCEPAR board constituting a channel of political power between such cooperatives and the entity and the latter with the political institutions and authorities. Therefore, we verify that some institutional and social aspects strongly impact the recruitment of this cooperative elite and the constitution of the agro-industrial cooperativism as a political actor, a dimension of great relevance for addressing its economic importance.
\end{abstract}

Keywords: cooperativism, business cooperatives, agroindustry cooperatives, cooperative elite, Paraná, Union and Organization of Cooperatives of the State of Paraná.

\footnotetext{
1 Este artigo está relacionado a projeto de Bolsa de Produtividade em Pesquisa do CNPq.
} 


\section{Introdução}

A forma particular de cooperativismo que resulta na constituição de grandes empreendimentos econômicos já foi contemplada pela literatura ${ }^{2}$. Embora relevantes, as questões privilegiadas em geral estão relacionadas à gestão e à inserção no mercado e na sociedade desta forma de cooperativa. Neste artigo, propomo-nos a abordar uma dimensão ainda pouco contemplada, mas que é de grande relevância na história, no funcionamento e nos próprios resultados obtidos pelas cooperativas: a sua relação com a política e o Governo, em seus âmbitos locais, regionais e nacionais ${ }^{3}$. Enfim, até mesmo em função da importância e da complexidade das relações entre tais empreendimentos, a economia, o mercado e a sociedade, não há como desconsiderar suas implicações políticas e o processo de representação dos interesses dos cooperados, em especial quando se trata de grandes cooperativas empresariais ${ }^{4}$.

Diante da complexidade da relação entre cooperativas agroindustriais e a política, a questão que norteia este artigo trata de uma dimensão fundamental da relação de qualquer ator ou grupo social com a política, ou seja, a sua própria constituição enquanto ator político, necessária e anterior à própria ação. Mais especificamente, o nosso problema de pesquisa volta-se para os condicionantes do recrutamento dos dirigentes de cooperativas para a direção de sua entidade de representação política, momento fundamental no processo de defesa dos interesses dos cooperados e com fortes implicações sobre o próprio funcionamento, o impacto social e o desempenho econômico dessas cooperativas.

Para tanto, consideramos, de um lado, os aspectos institucionais, externos e internos, e, de outro, alguns dados sociais que caracterizam aqueles que assumem a direção de uma importante entidade de representação do cooperativismo agroindustrial. Portanto, analisamos algumas das condições decisivas para que um determinado grupo de cooperados seja revestido também da condição de representantes políticos de seus pares, portanto, enquanto a elite política deste coletivo.

Após uma breve discussão sobre os fundamentos teóricos de nossa análise, apresentamos como pretendemos analisar as cooperativas agroindustriais, seus presidentes e os dirigentes de sua entidade de representação política. Em seguida, descrevemos nossos procedimentos metodológicos. O segundo item trata das características do cooperativismo agroindustrial do Paraná, no qual se insere o nosso objeto. No terceiro item, abordamos os aspectos institucionais e sociais do recrutamento da elite cooperativista, a partir dos resultados de nossa pesquisa. Em seguida, comentamos sobre alguns aspectos da atuação desta entidade, exclusivamente com o objetivo de chamar a atenção para a importância política do Sindicato e Organização das Cooperativas do Estado do Paraná (OCEPAR) e desta elite. Por fim, apresentamos nossas considerações finais.

\footnotetext{
2 Considerando os estudos publicados no Brasil, inclusive muitos também tendo como objeto de pesquisa as cooperativas agroindustriais, podemos mencionar os trabalhos de Ilha et al. (2018), Binotto et al. (2013), Ensslin et al. (2014), Leite \& Duaibs (2017), Costa et al. (2012a, 2012b) e Crúzio (1999).

3 Simioni et al. (2009) chamam a atenção para a natureza política dos dirigentes de cooperativas, o que implica a importância das relações de lealdade entre estes e os cooperados. Rodrigues \& Guilhoto (2004) também destacam o papel das grandes cooperativas nas políticas fiscal e de desenvolvimento do Paraná. Por sua vez, Moreira et al. (2012) colocam a política enquanto parte dos desafios enfrentados pelas cooperativas, embora foque mais propriamente as relações internas às cooperativas.

${ }^{4}$ Estamos usando a expressão cooperativismo empresarial proposta por Costa \& Stöberl (2016) para nos referirmos às grandes cooperativas que, embora não sejam empresas no sentido de atividades privadas visando ao lucro de acionistas e proprietários, possuem grande relevância no setor econômico em que atuam e uma complexidade gerencial, administrativa e trabalhista semelhante à encontrada em grandes sociedades empresárias. Os autores também se reportam à questão da relação entre cooperativismo empresaria/ e política. Aqui consideramos o cooperativismo agroindustrial como um tipo específico de cooperativismo empresarial.
} 


\section{Fundamentação teórica}

Ao tratarmos da ação política de um dado grupo ou ator social, deparamo-nos com uma vasta literatura, em geral associada à Ciência Política. Entretanto, as particularidades do cooperativismo empresarial exigem ajustes no uso das correntes e conceitos sociológicos presentes nesta literatura. Isso remete ao desafio de construir estratégias e categorias analíticas específicas e que tenham eficácia explicativa na análise de casos históricos. Por exemplo, do ponto de vista marxista, a ideia da relação entre as particularidades da atividade econômica de um dado grupo e a sua constituição enquanto ator político é sugestiva para pensarmos o caso do cooperativismo agroindustrial, dado que a lógica empresarial complexa deste tipo de cooperativismo certamente impacta no processo de sua constituição enquanto ator político e na sua relação com o Estado, ainda mais que tais cooperativas contratam um grande número de trabalhadores ${ }^{5}$.

Por sua vez, Max Weber também não trata diretamente da ação política do cooperativismo, mas igualmente traz em suas proposições gerais alguns elementos interessantes para os nossos objetivos, dos quais destacamos o seu conceito geral de política, o que nos dá uma referência para pensarmos o ator político como aquele que exerce a direção do Estado ou a influência sobre tal exercício. Desta forma, o cooperativismo empresarial, ao buscar ao menos exercer influência sobre autoridades e instituições do Estado, apresenta-se enquanto um ator político. Outro conceito weberiano que podemos utilizar para tratar de nosso problema de pesquisa é o de carisma, que, como veremos mais adiante, é importante para pensarmos as características da elite cooperativista. Por fim, o conceito de classe social de Weber, embora seja mais genérico ao se referir às condições econômicas e às posições nas relações de mercado, remete-nos a necessidade de atentar para as particularidades destas condições e posições do cooperativismo empresarial (Weber, 1991).

Quanto ao Neoinstitucionalismo, que enfatizaria os condicionantes institucionais sobre o processo de formulação das estratégias e da própria constituição dos cooperados enquanto ator político coletivo, parece ser insuficiente diante das particularidades do cooperativismo por deixar de lado fatores econômicos, sociais e culturais, ou até filosóficos, do coletivo composto pelos cooperados ${ }^{6}$. Além disso, a forma institucional de ação política das cooperativas, mesmo que possa ter semelhanças com as entidades sindicais ou associativas patronais, possui especificidades, sejam legais, sejam organizacionais ${ }^{7}$. Mas isso não significa a possibilidade de deixar de lado a importância dos condicionantes institucionais e seu impacto no processo de constituição do cooperativismo enquanto ator político.

E quando tomamos as proposições de Mancur Olson, podemos considerar que, se não há obrigação de os produtores se associarem em cooperativas, essas se constituiriam a partir do que o autor chama de "incentivos seletivos", no caso, os benefícios advindos do cooperativismo, e isso seria a base não apenas da própria existência das cooperativas como também de sua constituição enquanto ator político, o que, segundo o autor, seria um "subproduto" daqueles "incentivos". Haveria uma "venda casada", na expressão do autor, ou seja, benefícios políticos advindos e associados à ação coletiva por motivos econômicos, o que, segundo o autor, só faz

\footnotetext{
${ }^{5}$ Ver os trabalhos clássicos de Marx, O Dezoito de Brumário de Luís Bonaparte e As lutas de classe na França, bem como as proposições de Nicos Poulantzas (1977).

${ }^{6}$ Como exemplo de análises sobre as diversas correntes que em geral são associadas ao neoinstitucionalismo na Ciência Política, podemos destacar as de March \& Olsen (2008) e de Immergut (1998). Para a nossa discussão, podemos nos ater à descrição feita por Robert Putnam (1996), ou seja, o neoinstitucionalismo partiria da premissa de que as instituições são as variáveis independentes do comportamento, das estratégias e das ações dos atores políticos, e que a história é a variável independente do processo de constituição das instituições.

${ }^{7}$ Costa \& Stöberl (2016) analisam os aspectos legais e institucionais relativos a esse processo no Brasil.
} 
sentido para grandes grupos econômicos. Podemos destacar também que Olson, quando fala de cooperativismo, refere-se a grandes empreendimentos de produtores rurais americanos das primeiras décadas do século XX (Olson, 1999).

Se isso nos ajuda a pensar o processo de constituição das cooperativas em si, devemos considerar que o próprio Olson não desenvolve uma análise que nos indique uma estratégia para analisá-las como atores políticos. De um lado, o autor não se debruça sobre a ação política do grande cooperativismo rural americano e chama a atenção para o caráter limitado das suas "atividades lobísticas". Como veremos, o cooperativismo agroindustrial brasileiro parece ser um caso diferente. E, de outro, Olson não analisa a relação entre tais cooperativas e as políticas públicas, muito menos aqueles que exercem o papel de representação política destas cooperativas.

Em suma, estamos nos referindo a um agente econômico específico, ainda muito pouco estudado em sua dimensão política, e que não pode ser reduzido à sua condição de classe ou de patronato ou de empresariado, nem aos aspectos institucionais de sua ação política ou aos incentivos seletivos de sua constituição. Isso exige a criação de novas categorias e estratégias analíticas, ainda que a partir do diálogo com abordagens que possam ser sugestivas, no sentido de produzir um referencial teórico que tenha capacidade explicativa, bem como a definição com precisão do problema de pesquisa.

\subsection{A questão da elite política do cooperativismo}

Embora os breves comentários acima nos tragam elementos importantes para pensarmos a constituição do cooperativismo empresaria/enquanto ator político, entendemos que nossos objetivos específicos podem ser alcançados a partir das proposições que caracterizam os estudos de grupos minoritários, cuja base é a chamada Teoria das Elites ${ }^{8}$. Desde já, deve ficar claro que não entendemos que esse seja o único caminho ou que ele dê conta de toda a complexidade e de todas as dimensões da relação entre cooperativismo e política, mas sim que nossa opção foi analisar o processo de constituição da elite política do cooperativismo agroindustrial.

Em primeiro lugar, aqui estamos entendendo elite política enquanto o grupo minoritário que se destaca no exercício da representação política de um dado coletivo social. Este grupo não só está vinculado a este coletivo como também é por ele selecionado e em geral dele decorre. Em segundo lugar, o estudo do processo de constituição dos dirigentes da entidade de representação daqueles que se associam em grandes cooperativas empresariais passa pela questão do seu recrutamento. Aqui remetemos ao sentido corrente na literatura que estuda elite, que vai da obra clássica de Gaetano Mosca (1992), ao se referir ao processo de formação do que chama de "classe dirigente", aos estudos de caso sobre elites específicas no Brasil ${ }^{9}$.

Nesta literatura, a questão do recrutamento remete ao processo de seleção daqueles indivíduos que formam uma dada elite. Refere-se à abordagem de um aspecto fundamental para o estudo e a caracterização das elites e, portanto, central nos objetivos deste trabalho. Portanto, diz respeito aos aspectos institucionais e sociais correlatos à seleção daqueles que vão ocupar os cargos políticos, seja no Estado, seja nas associações e entidades que representam

\footnotetext{
8 Os clássicos da Teoria das Elites, a saber, Gaetano Mosca (1992), Vilfredo Pareto (1966) e Robert Michels (1982), desdobraram-se em diversos estudos mais recentes, como os de Wright Mills (1981) e Robert Dahl (1961) e também no Brasil. Não cabe aqui entrar no debate sobre a Teoria das Elites ou sobre as elites políticas, bastando fazer referência a trabalhos que tentam estabelecer as principais estratégias de análise dos diversos tipos de elites, por exemplo, Codato \& Perissinotto (2011, 2015).

9 Apenas como exemplo de análises sobre recrutamento de elites no Brasil, podemos citar Grynszpan (1999), Coradini (2006), Codato et al. (2016) e Codato \& Perissinotto (2015).
} 
interesses sociais, ou, como diz Daniel Gaxie, à ocupação, com maior ou menor competição, "das posições de poder político" e de "autoridade política" (Gaxie, 2012).

Assim, a noção de elite política, remete àqueles que exercem a representação política de um determinado grupo ou coletivo. Aqui adotamos as proposições de Wright Mills (1981) sobre a relevância do critério posicional para o estudo das elites, que, basicamente, indica a sua localização a partir dos cargos e posições formais que ocupam ${ }^{10}$. Além do aspecto posicional, coloca-se como de grande relevância na análise do processo de recrutamento a verificação das diferenças entre as elites e os coletivos dos quais decorrem, as quais indicam a existência de filtros ou características sociais, adstritas e adquiridas (Keller, 1967), que, por sua vez sugerem quais são as trajetórias ou "vias" (Giddens, 1974) pelas quais os membros das elites devem percorrer para chegarem a esta condição.

Outra categoria analítica importante em nossa análise, a qual remete ao Neoinstitucionalismo, é a noção de formato institucional, que se refere às particularidades organizacionais ou aos aspectos institucionais internos e externos a uma dada instituição, no caso, vinculada a um determinado coletivo e suas características sociais, econômicas e culturais e os aspectos institucionais característicos das leis e do político como um todo. Isso é relevante em função do impacto que tem sobre o recrutamento das elites, a definição dos interesses deste coletivo social, a natureza de sua ação política, suas estratégias e até seus valores ${ }^{11}$.

Por fim, entendemos que essa Sociologia Política do cooperativismo empresarialse apresenta como a estratégia mais produtiva de análise de nosso objeto e de tratamento de nosso problema de pesquisa, dado que combina a consideração de variáveis de natureza institucional, política e socioeconômica ${ }^{12}$. Feitas as considerações teóricas, essa discussão tem outro desdobramento que é central no trabalho de construção das categorias analíticas que deem conta de nosso problema da pesquisa, a noção de elite cooperativista.

\subsection{Os dirigentes de cooperativas empresariais e de suas entidades de representação: empresários, patronato, elite econômica ou elite empresarial?}

Ao tratar da questão das elites ligadas a atividades empresariais, Paulo Costa distingue a elite econômica, composta pelos altos dirigentes de grandes empresas, da elite empresarial, composta pelos dirigentes de entidades de representação, sindicais ou associativas. Ainda que todos sejam empresários e ocupem a condição de elite, distinguem-se em função dos cargos, das instituições (empresas e entidades de representação), das prerrogativas e das competências exigidas (Costa, 2014). Dada as particularidades das cooperativas empresariais, estas categorias podem servir como referência, mas não se encaixam perfeitamente.

Certamente, os presidentes de grandes cooperativas concentram relevantes poderes e responsabilidades administrativas e gerenciais, estabelecidos na própria Lei das Cooperativas ( $n^{\circ} 5.764 / 71$ ) e corroborados pelos seus estatutos sociais. Neste sentido, estes indivíduos não são apenas os representantes da sociedade cooperativa, mas sim os principais condutores de uma complexa estrutura econômica e administrativa ${ }^{13}$. Portanto, atuam nas decisões fulcrais

\footnotetext{
${ }^{10}$ Sobre as metodologias de identificação das elites, ver Codato (2015).

${ }^{11}$ A noção de formato institucional foi trabalhada por Costa (2005) e Costa \& Borck (2019), e aqui está sendo adaptada aos objetivos deste artigo.

${ }^{12}$ Sobre a questão da Sociologia Política, ver Codato \& Perissinotto (2011); e Perissinotto (2004). Em função das especificidades dos objetivos deste artigo, não trataremos particularmente da dimensão cultural que também faz parte desta abordagem. Sobre este ponto, ver o estudo de Paulo Stöberl (2019).

${ }^{13}$ Como algumas cooperativas agroindustriais estão entre as maiores indústrias do país nos levantamentos da imprensa especializada, seus presidentes foram incluídos na pesquisa International Management Studies, da Universidade de Heidelberg, Alemanha, que analisou aspectos da trajetória pessoal, profissional e os valores dos CEOs de grandes indústrias do Brasil, considerados como elite econômica (Valarini \& Pohlmann, 2013).
} 
da sociedade cooperativa e são os responsáveis pelos seus rumos e estratégias industriais e de mercado, além de presidirem os colegiados diretivos e as assembleias anuais de cooperados.

Mas uma característica decisiva que distingue os presidentes de cooperativas empresariais dos CEOs é que, além de conhecer o negócio e o mercado relacionado à atividade da cooperativa, eles enfrentam a cada quatro anos eleições paritárias para se manterem nos cargos. A capacidade eleitoral está pulverizada pela singularidade do voto de cada cooperado, por sua vez atrelado simplesmente à matrícula na cooperativa, e não ao capital ou volume de produção de sua propriedade, não havendo a figura do grupo majoritário em termos societários. Assim, isso se assemelha a uma eleição política. Entretanto, o candidato deve cumprir três condições: ser cooperado, ser detentor de competências gerenciais e ser dotado de carisma eleitoral (Weber, 1993), dado que os presidentes são eleitos para gerenciar as grandes cooperativas, e, estando ou não na direção da entidade de representação política, devem defender os interesses de todos os cooperados perante as autoridades políticas.

A evidência mais forte do carisma se dá exatamente neste aspecto, institucionalmente estabelecido, ou seja, a necessidade de não apenas possuir competências administrativas, mas também de convencer seus pares de que as possui e de ser capaz de exercer a representação política, da cooperativa ou do cooperativismo. Convém lembrar que o carisma político é uma das possíveis manifestações deste fenômeno. Isso nos permite pensar que ele pode se dar mesmo quando não se trata daquilo que o próprio Weber define como política: a direção do Estado e a influência que se exerce em tal sentido (Weber, 2015), dado que se trata de uma relação interna ao grupo dos cooperados. Em suma, o que pretendemos destacar ao recorrer ao conceito de carisma é a importância que Weber dá ao "caráter exemplar de uma pessoa", reconhecido por aqueles que a escolhem como um chefe e nela confiam como um líder, institucionalmente estabelecido, e não as características que marcam o tipo puro ideal de dominação carismática (Weber, 1991).

Por sua vez, os presidentes de grandes cooperativas empresariais que vão ocupar a direção da entidade de representação, a elite cooperativista, devem ser bem-sucedidos também no processo de seleção daqueles que vão ocupar esses cargos diretivos. Portanto, há elementos típicos de uma elite empresarial entre os eleitos para representar as cooperativas. Enfim, a articulação entre características de elite econômica e de elite empresarial e de singularidades próprias do cooperativismo é uma das particularidades da elite cooperativista, principalmente quando consideramos a relação entre esta e a entidade de representação do cooperativismo, como veremos mais adiante ${ }^{14}$.

A já vasta literatura sobre o empresariado no Brasil tem utilidade relativa quando consideramos as particularidades das cooperativas industriais e de sua elite ${ }^{15}$. Para os nossos interesses, destacamos os trabalhos de Sônia Regina de Mendonça $(2002,2010)$. Segundo a autora, na década de 1990, o cooperativismo, através da ação política de sua entidade nacional, a Organização das Cooperativas Brasileiras (OCB), apresentava-se como "força hegemônica do patronato rural brasileiro".

Entendemos que os dirigentes das cooperativas agroindustriais e o "patronato rural", mesmo que possam atuar conjuntamente, são grupos distintos, seja enquanto setores econômicos, seja quanto à natureza e à figura jurídica das instituições em que atuam, seja na forma de representação política. Como é sabido, o cooperativismo pode se apresentar em

${ }^{14}$ Ver item 3.2.

${ }^{15}$ Não cabe aqui comentar esta literatura, a qual vem desde os trabalhos clássicos de Fernando Henrique Cardoso (1964), Luciano Martins (1968) e Luiz Carlos Bresser-Pereira (1974), passando por Eli Diniz \& Renato Boschi (Szwako et al., 2016), Maria Antonieta Leopoldi (Leopoldi, 2000) e Angela de Castro Gomes (1979), até os trabalhos mais recentes de Wagner Mancuso (2007a, 2007b). 
vários outros segmentos (crédito, transporte, consumo, trabalho, saúde etc.) e comportar atividades econômicas de portes diferentes. Além do mais, embora não pretendamos tratar aqui desta questão, atribuir à OCB a hegemonia da representação patronal, como é feito por Sônia Mendonça, é temerário. Tal atribuição implicaria a desconsideração, de um lado, dessas diferenças, e de outro, do fato de que as entidades representativas do patronato rural, tais como a Sociedade Rural Brasileira e a Confederação Nacional da Agricultura, têm atuado de forma coordenada, ao menos nos últimos dez anos, no Congresso Nacional através da Frente Parlamentar da Agricultura (FPA). Por fim, há que se considerar a frente parlamentar específica do cooperativismo, a Frente Parlamentar do Cooperativismo(FRENCOOP), a despeito de alguns parlamentares atuarem nas duas frentes.

Além disso, como é sabido, "cooperativismo" possui duas acepções. A primeira remete a uma doutrina corporificada no conjunto de princípios que deveriam reger o comportamento do homem integrado naquele sistema, o solidarismo ${ }^{16}$. A segunda o concebe como sistema de organização econômica que visa eliminar os desajustamentos oriundos dos excessos da intermediação capitalista (Franke, 1973). Assim, seria uma alternativa ao sistema capitalista ou outro modelo de posse dos meios privados de produção e de distribuição de riquezas, porém, distinto do socialismo. Sendo assim, o braço econômico do cooperativismo é a cooperativa, enquanto o braço econômico do capitalismo é a empresa. A cooperativa é o conjunto de produtores (economias individuais) e seu objetivo é eliminar o intermediário entre o produtor e o mercado.

Portanto, no plano dos princípios, não se pode tratar a cooperativa como uma empresa, nem o seu dirigente como empresário, dado que as atividades e seus respectivos dirigentes seriam figuras diferentes e regidos por ethos diversos. Além disso, a legislação brasileira classifica, delimita e diferencia tais tipos ou grupos de atividades, sendo a cooperativa uma sociedade simples e a empresa uma sociedade empresária, caracterizada pela busca do lucro.

Por sua vez, ainda que atuem no mercado capitalista, as cooperativas que se dedicam ao agronegócio não podem ser classificadas e analisadas como agropecuárias ou rurais e seus dirigentes enquanto "patronato rural", mesmo que tenham que lidar com questões patronais. E mesmo a classificação das cooperativas agrícolas e pecuárias como setor econômico se mostra complicada, na medida em que as grandes cooperativas que aqui estudamos possuem uma natureza agroindustrial. Ou seja, em uma categorização inicial, ou até para a imprensa especializada, seriam indústrias. Aliás, no que diz respeito à representação política, por um lado, não integram as entidades de representação sindical nem do setor industrial, nem do setor agropecuário, tais como os sindicatos, federações e confederações, e nem das entidades associativas, como as associações comerciais e industriais. E, por outro lado, possuem sua própria estrutura sindical ${ }^{17}$. Outro detalhe importante em relação à elite cooperativista é que, no âmbito de sua atividade gerencial, o presidente de cooperativa só está abaixo da assembleia e tende a aglutinar as condições que em uma empresa são as de CEO e do conselho de administração. A isso se acrescenta o aspecto que aqui analisamos, ou seja, o seu papel enquanto representante político dos cooperados, ou seja, de elite política do cooperativismo.

${ }^{16}$ Charles Gide (1847-1932) atribuiu ao cooperativismo a base de sua doutrina, sendo o solidarismo enunciado por Lèon Bourgeois na teoria do quase-contrato, como base teórica das proposições do cooperativismo desenvolvidas pela chamada Escola de Nimes, na França (Gide \& Rist, 1949; Gide, 1955).

${ }^{17}$ As cooperativas estão inseridas em uma estrutura que se poderia chamar de híbrida, pois congrega ao mesmo tempo elementos compulsórios de registro e ingresso na entidade de representação, elementos associativos desta entidade, e uma natureza sindical, presentes na mesma entidade. Além disso, possuem um sistema sindical patronal próprio, a Confederação Nacional das Cooperativas (CNCOOP), constituída de Federações, a exemplo da Federação e Organização das Cooperativas do Estado do Paraná (FECOOPAR). Quanto à organização sindical, pode-se afirmar que segue uma estrutura formal análoga à das outras categorias, a exemplo das Confederação Nacional da Indústria (CNI) e da Confederação Nacional da Agricultura (CNA). 
Por fim, devemos levar em conta que, de um lado, tais dirigentes são iguais aos representados na condição de cooperados, mas, de outro, como vimos acima, possuem características que os diferenciam do coletivo do qual decorrem, principalmente: 1- por terem a capacidade de assumir a direção de empreendimentos econômicos que são semelhantes às grandes empresas, e que com elas se relacionam no mercado, 2- por terem sido eleitos de forma direta e igualitária pelos seus pares, e 3-por exercerem o papel de representantes dos cooperados junto às autoridades e instituições políticas. Isso é muito relevante na análise deste tipo de cooperativismo e de seu protagonismo político, o que, por sua vez, é fundamental para tratar de sua ação política e até de sua eventual força ou influência política.

Em suma, os dirigentes das cooperativas agroindustriais não são nem empresários ou, no caso, "patronato rural", nem estritamente dirigentes de entidades de representação patronal, sindical ou associativa. Neste sentido, não podem ser reduzidos nem à elite econômica, nem à elite empresarial, embora guardem semelhanças e relações com ambas. No Quadro 1 a seguir, apresentamos uma comparação entre a elite econômica, a elite empresariale aqueles que fazem parte de nosso objeto de pesquisa, a elite cooperativista, a partir de aspectos que as caracterizam, mais particularmente, o que está sob sua gestão, como são recrutados, quais são seus principais objetivos e como se relacionam com a política e os trabalhadores.

Quadro 1 - Comparação entre as elites econômica, cooperativista e empresarial

\begin{tabular}{|c|c|c|c|c|c|}
\hline & Gestão & Recrutamento & $\begin{array}{l}\text { Resultado } \\
\text { almejado }\end{array}$ & $\begin{array}{c}\text { Relação com a } \\
\text { política }\end{array}$ & $\begin{array}{l}\text { Relação com } \\
\text { trabalhador }\end{array}$ \\
\hline $\begin{array}{l}\text { Elite } \\
\text { econômica }\end{array}$ & Grande empresa & $\begin{array}{l}\text { Promoção ou } \\
\text { contrato }\end{array}$ & $\begin{array}{l}\text { Lucro para } \\
\text { acionistas }\end{array}$ & $\begin{array}{l}\text { Contatos com } \\
\text { autoridades ou } \\
\text { entidades de } \\
\text { representação } \\
\text { para defender os } \\
\text { interesses dos } \\
\text { acionistas }\end{array}$ & Patronal \\
\hline $\begin{array}{l}\text { Elite } \\
\text { cooperativista }\end{array}$ & $\begin{array}{l}\text { Empreendimento } \\
\text { econômico } \\
\text { complexo }\end{array}$ & $\begin{array}{l}\text { Eleição pelos } \\
\text { cooperados } \\
\text { (carisma } \\
\text { eleitoral e } \\
\text { político) }\end{array}$ & $\begin{array}{l}\text { Subsidiário: } \\
\text { rentabilidade e } \\
\text { sustentabilidade } \\
\text { para } \\
\text { cooperados }^{18}\end{array}$ & $\begin{array}{l}\text { Contatos com } \\
\text { autoridades } \\
\text { para defender } \\
\text { os interesses da } \\
\text { cooperativa e dos } \\
\text { cooperados }\end{array}$ & Patronal \\
\hline $\begin{array}{l}\text { Elite } \\
\text { empresarial }\end{array}$ & $\begin{array}{l}\text { Entidade de } \\
\text { representação } \\
\text { (sindical ou } \\
\text { associativa) }\end{array}$ & $\begin{array}{l}\text { Eleição pelos } \\
\text { representados } \\
\text { (carisma } \\
\text { eleitoral e } \\
\text { político) }\end{array}$ & $\begin{array}{l}\text { Defesa dos } \\
\text { interesses dos } \\
\text { associados }\end{array}$ & $\begin{array}{l}\text { Contatos com } \\
\text { autoridades para } \\
\text { defender os } \\
\text { interesses dos } \\
\text { associados e/ou } \\
\text { do setor ao qual } \\
\text { pertence }\end{array}$ & Interlocução \\
\hline
\end{tabular}

Fonte: os autores

\section{3 - Os procedimentos metodológicos}

O nosso objeto é o Sindicato e Organização das Cooperativas do Estado do Paraná (OCEPAR), considerando o período de 1996 a 2017. Além da revisão da literatura em busca de contribuições para o tratamento das questões teóricas e sobretudo da construção das categorias analíticas que

${ }^{18} \mathrm{~A}$ literatura sobre cooperativismo se refere a este aspecto como vantagem do serviço, ou seja, vantagens decorrentes da prestação de serviços oferecida pela cooperativa. Ver Franke (1973) e Stöberl (2018). 
dessem conta das especificidades do objeto, e em particular do nosso problema de pesquisa, nossa metodologia implicou fundamentalmente a análise de documentos desta entidade, de fontes sobre informações a respeito das atividades do setor de atuação da OCEPAR e de outras entidades do cooperativismo. Foram usados também dados sobre a economia paranaense e material de imprensa especializada, bem como a utilização parcial de dados obtidos através de entrevistas com diretores da OCEPAR, sempre à luz dos objetivos e dos limites deste artigo.

\section{O cooperativismo do setor agroindustrial: o caso do Paraná}

Algumas cooperativas agroindustriais do Paraná se diferenciam das demais pelo seu gigantismo e potencialidade de mercado, dispondo de grande quantidade de grãos e de proteína animal industrializada ou comercializada a granel. Trata-se de relevantes players da economia nacional, cuja situação financeira é reconhecida no mercado como um caso de "sucesso empresarial", e que a mídia especializada em agronegócio e grandes empresas coloca em posições de destaque em seus rankings, tanto da indústria quanto do agronegócio. Enfim, estas cooperativas não são apenas um conjunto estável de produtores, mas grandes empreendimentos econômicos que figuram entre as maiores empresas brasileiras, com faturamento anual superior a 1 bilhão de reais, como indica o levantamento da revista Exame de 201619.

A escolha do caso do Paraná se deu também em função de sua tradição agropecuária, que é o segundo maior produtor de grãos e de suínos e o primeiro em produção de proteína animal de frango. Ou seja, 14 das 17 maiores cooperativas agroindustriais do Brasil estão no Paraná (Tabela 1). As Tabelas 1 e 2, extraídas de uma publicação vinculada ao cooperativismo paranaense, apresentam a posição das cooperativas agroindustriais no Paraná no rol nacional, respectivamente nos anos 2014/2015 e 2016/2017. A Tabela 3 apresenta a posição na região Sul e a Tabela 4 a posição das cooperativas agroindustriais do estado entre as maiores empresas do Agronegócio (2016 e 2017). Esses dados comprovam não apenas a sua relevância econômica, como também o fato de que há uma curva de crescimento20.

Tabela 1 - Posição das cooperativas agroindustriais do Paraná no ranking de empresas (2014 e 2015)

\begin{tabular}{|cccc|}
\hline \multicolumn{4}{c|}{ Cooperativas do PR entre as 1000 maiores empresas do Brasil } \\
\hline POSIÇÃO 2015 & POSIÇÃO 2014 & Cooperativa & $\begin{array}{c}\text { Vendas líquidas (em } \\
\text { milhões de reais }\end{array}$ \\
118 & 54 & Coamo & $10.525,2$ \\
144 & 120 & C.Vale & $5.698,8$ \\
193 & 193 & Lar & $4.149,7$ \\
222 & 218 & Cocamar & $3.260,9$ \\
261 & 256 & Copacol & $2.937,0$ \\
265 & 283 & Agrária & $2.489,6$ \\
282 & 321 & Integrada & $2.417,8$ \\
319 & 319 & Castrolanda & $2.282,0$ \\
324 & 359 & Coopavel & $2.029,4$ \\
& 344 & Frimesa & $2.014,5$
\end{tabular}

Fonte: Retirado de Revista Paraná Cooperativo, ano 12, número 138, julho, 2016, p. 32.

\footnotetext{
${ }^{19}$ Na edição As melhores da Dinheiro Rural de 2016 (dezembro 2016/janeiro 2017), a cooperativa indicada como a melhor do ano é do Paraná, a COAMO, e das cinco cooperativas de melhor gestão financeira e de melhor gestão cooperativa, 4 são paranaenses: COAMO, COCAMAR, COPACOL e INTEGRADA. Este levantamento também indica que 12 das 14 cooperativas agroindustriais do Paraná estão entre as 500 maiores empresas do agronegócio.

${ }^{20}$ Esta tendência pode ser verificada em levantamento mais recente do Valor 1000 . Ver Sindicato e Organização das Cooperativas do Estado do Paraná (2019a).
} 
Tabela 1 - Continuação...

\begin{tabular}{|cccc|}
\hline \multicolumn{4}{c}{ Cooperativas do PR entre as 1000 maiores empresas do Brasil } \\
\hline POSIÇÃO 2015 & POSIÇÃO 2014 & Cooperativa & $\begin{array}{c}\text { Vendas líquidas (em } \\
\text { milhões de reais }\end{array}$ \\
334 & 378 & Frísia & $1.945,5$ \\
457 & 496 & Copagril & $1.347,5$ \\
462 & 535 & Coasul & $1.334,1$ \\
566 & 663 & Capal & $1.025,5$ \\
842 & 977 & Bom Jesus & 604,0 \\
887 & 874 & Coagru & 563,5 \\
965 & - & Unimed de Londrina & 490,4 \\
\hline
\end{tabular}

Fonte: Retirado de Revista Paraná Cooperativo, ano 12, número 138, julho, 2016, p. 32.

Tabela 2 - Posição das cooperativas agroindustriais do Paraná no ranking de empresas (2016 e 2017)

\begin{tabular}{cccc} 
POSIÇÃO 2017 & POSIÇÃO 2016 & Cooperativa & $\begin{array}{c}\text { Vendas líquidas } \\
\text { (em milhões de reais }\end{array}$ \\
46 & 42 & Coamo & $10.510,5$ \\
81 & 81 & C.Vale & $6.933,7$ \\
121 & 119 & Lar & $5.031,7$ \\
193 & 173 & Cocamar & $3.477,6$ \\
211 & 205 & Copacol & $3.272,9$ \\
254 & 240 & Castrolanda & $2.787,8$ \\
256 & 235 & Integrada & $2.706,0$ \\
259 & 251 & Agrária & 2692,4 \\
290 & 291 & Frimesa & $2.465,6$ \\
299 & 280 & Frísia & $2.380,8$ \\
341 & 303 & Coopavel & $2.112,3$ \\
453 & 432 & Copagril & $1.496,4$ \\
454 & 409 & Coasul & $1.488,6$ \\
455 & 423 & Cocari & $1.487,4$ \\
533 & 468 & Capal & $1.217,0$ \\
833 & 855 & Bom Jesus & 684,4 \\
865 & 882 & Unimed de Londrina & 608,6 \\
979 & & Coagru & 516,7 \\
\hline
\end{tabular}

Fonte: Revista Exame - publicado pela Revista Paraná Cooperativo. Ver Sindicato e Organização das Cooperativas do Estado do Paraná (2019b)

Tabela 3 - Posição das cooperativas agroindustriais: porte Região Sul (2014 e 2015)

\begin{tabular}{ccc} 
& Entre as 100 maiores da Região Sul \\
\hline POSIÇÃO 2015 & POSIÇÃO & Cooperativa \\
\hline 2 & 2014 & Coamo \\
10 & 5 & C.Vale \\
16 & 13 & Lar \\
22 & 19 & Cocamar \\
\hline
\end{tabular}

Fonte: Retirado de Revista Paraná Cooperativo, ano 12, número 138, julho, 2016, p. 32. 
Tabela 3 - Continuação...

\begin{tabular}{ccc} 
& Entre as 100 maiores da Região Sul \\
\hline POSIÇÃO 2015 & $\begin{array}{c}\text { POSIÇÃO } \\
2014\end{array}$ & Cooperativa \\
\hline 29 & 31 & Copacol \\
31 & 39 & Agrária \\
32 & 46 & Integrada \\
34 & 44 & Castrolanda \\
43 & 52 & Coopavel \\
45 & 49 & Frimesa \\
46 & 53 & Frísia \\
68 & 70 & Copagril \\
69 & 78 & Coasul \\
90 & - & Capal \\
\hline
\end{tabular}

Fonte: Retirado de Revista Paraná Cooperativo, ano 12, número 138, julho, 2016, p. 32.

Tabela 4 - Posição das cooperativas agroindustriais entre as maiores empresas do Agronegócio (2016 e 2017)

\begin{tabular}{ccc} 
POSIÇÃO 2017 & POSIÇÃO 2016 & Cooperativa \\
10 & 9 & Coamo \\
21 & 22 & C.Vale \\
32 & 33 & Lar \\
42 & 43 & Cocamar \\
46 & 49 & Copacol \\
55 & 57 & Castrolanda \\
56 & 55 & Integrada \\
57 & 61 & Agrária \\
65 & 73 & Frimesa \\
69 & 69 & Frísia \\
75 & 74 & Coopavel \\
101 & 104 & Copagril \\
102 & 95 & Coasul \\
103 & 99 & Cocari \\
131 & 114 & Capal \\
230 & 248 & Bom Jesus \\
276 & 212 & Coagru \\
292 & 294 & Primato \\
319 & - & Confepar \\
\hline
\end{tabular}

Fonte: Revista Exame - publicado pela Revista Paraná Cooperativo. Ver Sindicato e Organização das Cooperativas do Estado do Paraná (2019b).

Em sendo cooperativas paranaenses, é necessário focalizá-las também dentro do universo empresarial deste estado, a despeito de sua importância no âmbito nacional. Do faturamento de todas as indústrias do Paraná no ano de 2014, 24\% provêm de 14 cooperativas agroindustriais, percentual que pode representar até 9\% do PIB do Paraná. Em relação ao PIB agropecuário, as cooperativas representam 56\% (Sindicato e Organização das Cooperativas do Estado do Paraná, 2015). Por fim, destacamos que as 14 cooperativas agroindustriais apresentadas na Tabela 2 possuem em conjunto algo próximo a 120 mil cooperados e 60 mil empregados (Sindicato e Organização das Cooperativas do Estado do Paraná, 2015), o que é mais surpreendente 
quando consideramos que surgiram, na sua maior parte, no final dos anos 1960 e início dos 1970 (Instituto Paranaense de Desenvolvimento Econômico e Social, 1974)21.

O que pretendemos ressaltar é a relevância econômica, estadual e nacional, e a complexidade gerencial dos empreendimentos geridos pelos presidentes das grandes cooperativas empresariais paranaenses. A seguir, apresentaremos nossa análise do processo de seu recrutamento enquanto elite cooperativista.

\section{Os condicionantes institucionais e sociais do recrutamento da elite política do cooperativismo agroindustrial: o caso da OCEPAR}

Além dos dados econômicos relativos ao cooperativismo agroindustrial do Paraná, outro aspecto a ser destacado é a relevância institucional e política da entidade que é o nosso objeto. A OCEPAR congrega e representa tais cooperativas no estado, participa da representação do cooperativismo em âmbito nacional e é a entidade através da qual se concentra a ação política das cooperativas empresariais paranaenses.

A OCEPAR tem integrado a diretoria da OCB, tem atuado diretamente junto ao parlamento em assuntos relativos ao crédito agrícola, dívidas do setor e assuntos do agronegócio, conforme noticiado pelos periódicos eletrônicos das duas entidades, inclusive com a participação da diretoria da OCEPAR e não só do presidente da entidade, como comumente acontecia. E dos 14 diretores da atual gestão da OCEPAR, 10 são do setor agroindustrial, 3 do crédito e 1 da saúde. Portanto, a predominância do agronegócio na diretoria da entidade ainda persiste. As pequenas cooperativas, seja qual for o setor, também estão obrigatoriamente na Ocepar, portanto, votam na diretoria, mas nunca a integraram.

Daí a importância de se analisar o formato institucional do qual decorre o recrutamento dos membros da diretoria desta entidade. Como a OCEPAR está integrada à estrutura nacional de representação do cooperativismo, é necessário situá-la dentro desta estrutura. Para tanto, tecemos breves considerações sobre a entidade de representação nacional, dado que as entidades estaduais possuem natureza e formatos semelhantes, e algumas diferenças relevantes.

\section{1 - Os condicionantes legais da representação política do cooperativismo no Brasil}

Em 1971, a Lei Federal no 5.764 criou a Organização das Cooperativas Brasileiras (OCB), que é a entidade responsável pelo registro, compulsório, e pela ação política institucionalizada das 6.655 cooperativas do país, as quais são responsáveis por 376.795 postos de trabalho e congregam 13.230.960 cooperados (Organização das Cooperativas Brasileiras, 2015) ${ }^{22}$. Esta lei criou também o Sistema $O C B$, que, além da própria $O C B$, engloba a entidade sindical do cooperativismo, que é a Confederação Nacional das Cooperativas (CNCOOP) e o Serviço Nacional de Aprendizagem do Cooperativismo(SESCOOP Nacional). A presidência deste Sistema é exercida pelo presidente da OCB.

Além do caráter compulsório do registro estabelecido nesta lei, foi instituída a obrigatoriedade de unicidade de representação institucional das cooperativas de todo o país através da OCB. Entretanto, esta lei afastou da dimensão sindical deste Sistema o exercício da representação política do cooperativismo, como ocorre, por exemplo, com a CNI e a CNA, dado que os sindicatos, federações das cooperativas e a própria CNCOOP atuam estritamente no âmbito do direito

${ }^{21}$ Segundo a OCEPAR, em 2017 existiam 69 cooperativas do ramo agropecuário no Paraná, com 167.563 cooperados e 76.370 empregados. Ver Sindicato e Organização das Cooperativas do Estado do Paraná (2017).

${ }^{22} \mathrm{Em}$ relação a esse aspecto, trataremos também mais adiante da questão da UNICOPAS. 
coletivo do trabalho. Assim, a legislação que regula as cooperativas no Brasil estabeleceu esta estrutura sui generis, que combina entidade de representação, órgão técnico-consultivo do Governo e órgão de registro das sociedades cooperativas, e que reserva à OCB a representação política, cuja direção é exercida por cinco diretores eleitos, um por região geográfica do Brasil, dentre os presidentes das 27 Organizações Estaduais ${ }^{23}$. Em oposição à unicidade da representação, existem ações vindas de algumas cooperativas que se apoiam na reforma da lei cooperativista ${ }^{24}$, a qual criaria a dualidade de representação entre a OCB e a União Nacional das Organizações Cooperativistas Solidárias (UNICOPAS) ${ }^{25}$.

Por sua vez, a OCEPAR possui semelhanças e diferenças em relação à OCB. De sua criação em 1971 até 1995, a OCEPAR foi estritamente uma entidade de cooperativas, sob a forma compulsória de organização, das quais assumia a representação política, função exercida até hoje. A partir de 2016, em alguns casos, esse papel foi assumido pela Federação e Organização das Cooperativas do Estado do Paraná (FECOOPAR) ${ }^{26}$. Seus periódicos indicam que ela passou a se denominar Sistema OCEPAR para congregar ações das três entidades que a compõem: a OCEPAR organização, o SESCOP (serviço social autônomo) e a FECOOPAR (sindical), compondo as três faces de uma mesma entidade representativa do cooperativismo paranaense ${ }^{27}$.

O Estatuto da OCEPAR de 2002 estabelece como seu objetivo primordiala representação e a defesa dos interesses do sistema cooperativista paranaense perante as autoridades constituídas e a sociedade, além de exercer a representatividade sindical patronal das cooperativas paranaenses. Entretanto, o âmbito de atuação da OCEPAR abrange outros objetivos, como os de promoção, divulgação e desenvolvimento da doutrina cooperativista e a colaboração com o Governo estadual em políticas públicas relacionadas ao cooperativismo e ao desenvolvimento econômico do Paraná, além de exercer atividades de interesse das cooperativas, realizar projetos e levantamentos que visem atender às necessidades do cooperativismo e preservar a identidade e a unidade do Sistema Cooperativo28.

Em suma, além de descrever a estrutura institucional através da qual se constitui a representação política do cooperativismo empresarial aqui analisado, tais dados nos permitem concluir que a ação da OCEPAR voltada para o processo decisório das políticas públicas no estado se dá de

${ }^{23}$ A OCEPAR já ocupou por várias gestões passadas e desde 2016 vem ocupando a representação da Região Sul, fato que reforça a sua importância político-representativa regional e nacional.

${ }^{24}$ Mais detalhes no artigo 77 do Projeto de Lei n 519/2015, que tramita na Câmara dos Deputados.

25 A UNICOPAS é o resultado da união em 2014 de três organizações nacionais, a União Nacional das Cooperativas da Agricultura Familiar e Economia Solidária (Unicafes), a Central de Cooperativas e Empreendimentos Solidários (Unisol Brasil) e a Confederação das Cooperativas da Reforma Agrária do Brasil (Concrab). As cooperativas que integram tais organizações são ligadas à agricultura familiar, à economia solidária e à reforma agrária. As cooperativas analisadas neste trabalho estão todas dentro da OCB, através da OCEPAR.

${ }^{26}$ Neste trabalho não trataremos da FECOOPAR por dois motivos: (i) a OCEPAR assumiu a prerrogativa sindical em 1997, manteve-se como sindicato estadual de todos os ramos de cooperativa e abriu sua base para outros oito sindicatos e para uma federação, que deveria ter sido assumida pela OCEPAR, mas essa ideia não se concretizou. Entretanto, notamos que a OCEPAR mantém o comando desta prerrogativa, dado que seu presidente é também presidente da FECOOPAR, a sua diretoria compreende os presidentes de grandes cooperativas que já foram diretores da OCEPAR, e ela funciona em uma única sala da sede da OCEPAR; (ii) verificamos que, nas publicações do cooperativismo paranaense, a FECOOPAR está sempre atrelada estritamente à área das relações trabalhistas, firmando Convenções Coletivas de Trabalho, atuando junto aos nove sindicatos regionais patronais na celebração dos acordos ou ainda auxiliando as cooperativas na interlocução com o sindicato de empregados. Não encontramos sinais de ação política específica desses sindicatos regionais agropecuários patronais.

${ }^{27}$ Todavia, após uma alteração estatutária com o objetivo de se tornar também uma entidade sindical, a OCEPAR obteve em 1995 o registro de sindicato patronal de todos os ramos de cooperativas no Paraná, já que as cooperativas são consideradas empregadoras em relação aos seus trabalhadores. Antes desta prerrogativa obtida pela OCEPAR, as cooperativas eram representadas pelos sindicatos da indústria de alimentação ou do comércio.

${ }^{28}$ Assim, de um lado, o artigo $1^{\circ}$ do estatuto da OCEPAR menciona "governo" para referir-se ao âmbito estadual e seus poderes constituídos. E, de outro, a Constituição Estadual (Art. 148) confere à OCEPAR a condição de órgão de representação, com assento em todos os colegiados paritários do estado, e elenca o cooperativismo como uma atividade prioritária no Paraná. 
forma centralizada e concentrada em Curitiba e na OCEPAR, o que é reconhecido e ressaltado pela própria entidade (Setti, 2011). Isso implica a grande relevância política dos dirigentes desta entidade e a necessidade de estudar a sua composição, enquanto elite cooperativista.

\section{2 - O formato institucional do recrutamento da elite cooperativista: a composição dos cargos de direção da OCEPAR}

Como vimos acima, em função dos condicionantes legais e institucionais externos à OCEPAR, as questões relativas à ação política e aos posicionamentos relevantes do setor cooperativo paranaense são tratadas pela diretoria da OCEPAR, a qual é composta por 14 dirigentes de cooperativas registradas e com sede no Paraná, eleitos de quatro em quatro anos, em assembleia geral da entidade, sendo facultada a reeleição para apenas um mandato ${ }^{29}$.

Embora a OCEPAR tenha natureza jurídica organizacional e sindical, o seu estatuto estabelece que a composição de sua diretoria atende às questões de direito cooperativo e não de questões de direito coletivo do trabalho, aplicando-se as regras da lei cooperativista, a exemplo da vedação de terceiro mandato e da ausência da figura da filiação. Dito de outra forma, a OCEPAR assume uma estrutura sui generis, se comparada com as entidades sindicais, como a Federação das Indústrias do Estado do Paraná e a Federação da Agricultura do Paraná, na medida em que possui regras próprias e diferentes das previstas pela CLT. Mais especificamente, referimo-nos, de um lado, à forma de composição de sua diretoria, que se dá por eleição regional, e, de outro, aos eleitores, dado que são as cooperativas que votam.

Outra particularidade importante é que, embora a diretoria até hoje seja composta por dirigentes de cooperativas, a partir de 1996 a presidência da entidade passou a ser exercida por um "empregado" da OCEPAR, eleito pela assembleia das cooperativas, e que atua como "porta-voz" da entidade. Após a reforma estatutária de 2002, criou-se a figura da presidência executiva, que desde então é ocupada a partir deste critério ${ }^{30}$.

Para os nossos objetivos, é importante destacar que, dos 14 diretores, 10 são oriundos das cooperativas do ramo agropecuário ${ }^{31}$. A eleição só se realiza através de chapas previamente inscritas, cujos membros ocuparão os cargos na diretoria. Nas seis eleições que ocorreram de 1996 a 2015 (diretoria atual), verificamos que só houve a inscrição de chapas únicas, as quais foram eleitas por unanimidade.

A construção da chapa possui dois momentos distintos, ambos regulados pelo estatuto da OCEPAR. Inicialmente, cinco vagas são destinadas aos dirigentes (coordenadores regionais) que representam os chamados núcleos cooperativos correspondentes à divisão do estado em regiões (norte, noroeste, oeste, sudoeste e centro-sul), nos quais as sedes das cooperativas se localizam. São realizadas duas reuniões formais semestrais promovidas pela OCEPAR em cada um desses núcleos, sendo que no segundo semestre, antes do encerramento do mandato da diretoria, são eleitos/indicados os nomes dos coordenadores das cinco vagas relativas aos

${ }^{29} \mathrm{Em}$ 2016, existiam 222 cooperativas registradas, sendo 69 do ramo agropecuário (Sindicato e Organização das Cooperativas do Estado do Paraná, 2017).

${ }^{30} \mathrm{Em}$ 2016, por aposentadoria de seu titular, foi indicado outro empregado graduado da OCEPAR, que também era engenheiro agrônomo com carreira de mais de 20 anos dentro da estrutura da OCEPAR. De 2002 até 2015, o cargo foi exercido pela mesma pessoa.

${ }^{31}$ A regra de preenchimento das cadeiras da diretoria está disposta no artigo 19 do Estatuto da OCEPAR. De 1996 a 2015, das 14 cadeiras, 11 pertenciam a cooperativas agropecuárias. A partir da eleição de 2015, coube ao ramo agropecuário 10 cadeiras, pois o ramo de crédito passou a ocupar mais uma vaga, resultando na seguinte distribuição: 10 vagas para as cooperativas agropecuárias, 3 vagas para o ramo de crédito e 1 vaga para o ramo de saúde, ocupada pela UNIMED. 
núcleos. Tais coordenadores comporão a chapa para concorrer na assembleia. Como em geral só se constitui uma chapa, eles já podem se considerar eleitos para os quatro anos seguintes.

Em relação à escolha de candidatos pelos núcleos regionais, não existe um procedimento formal definido, pois a única versão do regimento interno destes núcleos disponível foi publicada em outubro de 1991, no jornal da OCEPAR, quando da criação dos núcleos regionais pelo então presidente da entidade, Inácio Donel. O objetivo então declarado era a descentralização das decisões e da representação ${ }^{32}$.

Mas a análise desta dinâmica e deste objetivo indica que houve um processo inverso, isto é, a manutenção da centralização. Embora a eleição dos futuros membros da diretoria se processe inicialmente em instâncias diversas e anteriores à assembleia geral (centralizada), nas quais ocorreriam possíveis disputas regionais, os cargos têm sido exercidos de forma centralizada e sediada em Curitiba, na sede da OCEPAR, no âmbito do colegiado, já que os pronunciamentos no interior pelo diretor da entidade, na maioria das vezes são feitos em nome da cooperativa que ele preside, e não em nome específico da OCEPAR.

A composição da chapa também leva em conta os principais ramos cooperativos estruturados na OCEPAR, bem como os segmentos organizados, cujo critério é o índice de participação na manutenção da entidade (percentual do montante total das contribuições recolhidas - critério estatutário) e nos ramos (agropecuário, crédito e saúde). Todavia, não encontramos casos de coordenadores de núcleos que não representem cooperativas agropecuárias.

As vagas na chapa são geralmente reservadas a presidentes de cooperativas de segundo grau, que congregam cooperativas de primeiro grau, a exemplo do crédito e saúde. No ramo agropecuário, este critério se mostra aplicável algumas vezes. Não há um mecanismo formal estruturado, o que nos leva a crer que isso decorra de outros arranjos, institucionais ou não. A composição das chapas indica que, na grande maioria dos casos, os candidatos aparecem em duas gestões sucessivas. Após este período, a vaga do núcleo é destinada ao presidente de outra grande cooperativa da região. Esse processo não exclui a presença na chapa e, portanto, na diretoria, de presidentes de cooperativas de outros setores, como os de saúde e crédito.

Em suma, além dos constrangimentos da legislação superior correlata ao cooperativismo no Brasil, podemos destacar dos aspectos institucionais do recrutamento da elite cooperativista da OCEPAR a natureza regional da eleição da diretoria pelas cooperativas, a formalização do predomínio numérico do setor agropecuário e as formas de construção de uma chapa única. Tais aspectos do formato institucional, a despeito de tentativas no sentido contrário, tenderam a reforçar a centralização do processo decisório na diretoria OCEPAR.

Além disso, verificamos que, a despeito da especialização e da profissionalização da presidência e consequentemente da gerência da entidade, exercida por engenheiros e técnicos, e da tentativa de descentralização do processo decisório, cabe à diretoria a condução política da OCEPAR. Isso reforça a relevância dos dirigentes das cooperativas agroindustriais e da sua predominância na direção da entidade. O processo de recrutamento desta diretoria resulta de uma concertação e de uma composição descentralizada da chapa que antecede a assembleia, que formalmente a elege. Isso indica que entre as características do formato instituciona/que vai selecionar a diretoria está a busca da construção de um consenso na composição da diretoria.

Por fim, os aspectos institucionais não impedem, mas reforçam e reproduzem a manutenção da superioridade numérica do ramo agropecuário e a centralização do processo decisório em Curitiba, indicando que isso decorre não apenas da sua relevância econômica, mas também

${ }^{32}$ Tais informações constam da ata da penúltima reunião da diretoria, antes de iniciar o ano em que se findam os mandatos. As reuniões são descentralizadas, ou seja, ocorrem em uma cooperativa por região, sendo ao final do processo lavrada uma ata única dos cinco encontros. Não foram detectados sinais de disputa ou conflitos. 
do formato institucional de seleção da elite cooperativista, o que reforça a hipótese de sua força política ${ }^{33}$.

\section{3 - As trajetórias e as características sociais da elite cooperativista}

Como vimos acima, os diretores da OCEPAR são na sua grande maioria os presidentes das 14 maiores cooperativas agropecuárias, o que pode ser comprovado pelo cruzamento dos nomes dos diretores da OCEPAR entre 1996-2017 com os nomes dos presidentes de cooperativas, apresentado na Tabela 5, tendo por referência os dados da revista Exame publicados em 2015. Na primeira coluna, esta tabela apresenta a posição no rol das maiores cooperativas, por ordem decrescente do faturamento em 2014. A segunda coluna traz o nome da cooperativa. Na terceira coluna, indicamos de quantas das seis últimas gestões da OCEPAR cada cooperativa participou naquele período. A quarta coluna informa quantas vezes os presidentes das cooperativas agroindustriais foram diretores da OCEPAR. Na quinta coluna, informamos a data de eleição dos presidentes em suas respectivas cooperativas.

Tabela 5 - Características das cooperativas paranaenses (1996-2017)

\begin{tabular}{ccccc}
$\begin{array}{c}\text { POSIÇÃO NO } \\
\text { ROL }\end{array}$ & COOPERATIVA & $\begin{array}{c}\text { NÚMERO DE } \\
\text { GESTÕES }\end{array}$ & $\begin{array}{c}\text { CARGOS NA } \\
\text { DIRETORIA } \\
\text { DA OCEPAR }\end{array}$ & $\begin{array}{c}\text { INÍCIO DO } \\
\text { MANDATO NA } \\
\text { COOPERATIVA }\end{array}$ \\
\hline 1 & COAMO & 6 & 4 & 1975 \\
2 & C.VALE & 5 & 4 & 1995 \\
3 & LAR & 0 & 0 & 1991 \\
4 & COCAMAR & 6 & 4 & 1989 \\
5 & COPACOL & 3 & 2 & 1998 \\
6 & AGRARIA & 3 & 2 & 1999 \\
7 & INTEGRADA & 2 & 1 & 2014 \\
8 & CASTROLANDA & 3 & 3 & 1998 \\
9 & COOPAVEL & 3 & 3 & 1995 \\
10 & FRIMESA & 3 & 2 & 1997 \\
11 & FRÍSIA/BATAVO & 4 & 2 & 2007 \\
12 & COPAGRIL & 2 & 2 & 2000 \\
13 & COASUL & 3 & 2 & 1976 \\
14 & CAPAL & 0 & 0 & 2011 \\
15 & BOM JESUS & 4 & 4 & 1995 \\
\hline
\end{tabular}

Fonte: Rol das 14 cooperativas com faturamento superior a 1 bilhão de reais/ano - exercício 2014, publicado em 2015 pela revista Exame - Maiores e Melhores.

Um primeiro aspecto que se destaca é a coincidência entre os presidentes das cooperativas agroindustriais e a direção da OCEPAR, a elite cooperativista. Outro detalhe importante é que as figuras individuais têm importância no processo de recrutamento, portanto, na ocupação dos cargos de representação política da entidade, o que ocorre de forma particular no caso da cooperativa Bom Jesus.

${ }^{33}$ Embora não pretendamos tratar esta questão, a predominância das cooperativas agroindustriais poderia explicar a forte atuação da OCEPAR na defesa deste setor, evidenciada pela quantidade de notícias a ele relacionadas nos informes diários da entidade, mas também pode ser a consequência de um passado no qual as cooperativas agropecuárias eram a força motriz do cooperativismo. 
A Tabela 5 indica que dirigentes da COAMO e da COCAMAR integraram a diretoria de todas as gestões ${ }^{34}$. A cooperativa C. Vale integrou cinco gestões. A cooperativa BATAVO, que atualmente se chama FRÍSIA, integrou quatro gestões (1996, 2000, 2011 e 2015), cujo atual presidente está no cargo desde 2007 (eleito para 2011 e reeleito para 2015). A COOPAVEL e a CASTROLANDA integraram três gestões (2003, 2007 e 2015). A COASUL também integrou três gestões (2007, 2011 e 2015). A FRIMESA integrou três gestões (2000 e 2007 e 2011) e não está participando da atual. A AGRARIA participou de três gestões (1996, 2007 e 2011). A COPAGRIL integrou as duas últimas gestões (2011 e 2015). A COPACOL integrou duas gestões (2003 e 2007). A INTEGRADA está na atual gestão. A LAR e a CAPAL não participaram de nenhuma gestão35.

Esses dados também comprovam a conexão entre a presidência das maiores cooperativas do setor agroindustrial e a direção da OCEPAR ${ }^{36}$. Tal processo sugere que a diretoria cresceu em poder e assumiu maior importância na indicação das pautas-chave que a OCEPAR deveria buscar, ao invés da sua fragilização ou concentração de poderes na presidência. Entendemos que esse processo representou uma mudança institucional que tinha o objetivo de concentrar e profissionalizar não apenas a gestão, como também a ação política, no caso, na diretoria da OCEPAR.

Assim, constatamos que os aspectos institucionais acima indicados mostram a importância de um aspecto da trajetória profissional e da carreira dos membros da elite corporativista, ou seja, a participação na alta gestão de grandes cooperativas agroindustriais, o que fomenta um processo de certa profissionalização da atividade de representação política.

Por fim, em relação aos aspectos sociais, a análise de algumas características do grupo de presidentes que predominam na diretoria da OCEPAR, demonstra que todos são homens, com idade superior a 50 anos, casados e com filhos. Dos 14 presidentes, 13 são brancos e 1 amarelo e na sua maioria declaram seguir alguma religião. Embora a maioria tenha nascido e more no interior e seja filho ou neto de pequenos produtores rurais, tornaram-se grandes produtores rurais. Em relação à formação educacional, verificamos que a grande maioria dos dirigentes da OCEPAR é composta de engenheiros agrônomos e que todos possuem mais de quinze anos de carreira na cooperativa. Detectamos basicamente duas carreiras: a maioria exerceu cargo técnico de empregado na cooperativa antes de ser eleito para dirigente, e o outro grupo menor deriva de filhos de cooperados, portanto lideranças da própria cooperativa. Este segundo grupo é oriundo de cooperativas de colônia de imigrantes europeus.

Em suma, os dados acima analisados, de um lado, indicam uma grande homogeneidade(Mills, 1981) no processo de recrutamento desta elite, dada a sua trajetória ou carreira profissional

\footnotetext{
${ }^{34} \mathrm{Na}$ COAMO houve a substituição do representante nas gestões de 2003 e na de 2005, possivelmente pela vedação estatutária do terceiro mandato. Nas eleições de 2000 e 2011, a COCAMAR indicou outro diretor, provavelmente pelo mesmo motivo.

${ }^{35} \mathrm{~A}$ análise das chapas e gestões da OCEPAR no período de 1996-2017 indica que algumas cooperativas aparecem na composição nas Diretorias das entidades, mas não estão entre as 14 maiores cooperativas agroindustriais são: CLAC, COROL e CAMINSC em 1996; BOM JESUS, CAMINSC e COROL em 2000; BOM JESUS, COFERCATU, CAMDUL, COAGEL, COCEAL em 2003; COAGEL, COFERCATU, CONFEPAR em 2007; CONFEPAR e BOM JESUS em 2011; BOM JESUS em 2015. Considerando os dados de 2017, tais cooperativas podem ser divididas em dois grupos: (i) cooperativas que não existem mais ou estão em adiantado processo de liquidação, a saber, CLAC, COROL, CAMDUL, COCEAL e COAGEL, que foi incorporada pela COAMO; (ii) cooperativas cujos presidentes compuseram a diretoria (comando estatutário) para representar o núcleo regional ao qual pertenciam: CAMINSC, do núcleo sudoeste e COFERCATU e CONFEPAR, do núcleo Norte.

${ }^{36}$ Há outros aspectos interessantes para os objetivos deste artigo. Em primeiro lugar, a BOM JESUS, que não está entre as 14 maiores, está nas diretorias por 4 gestões (2000, 2003, 2011 e 2015). Em segundo lugar, a LAR, terceira maior cooperativa em termos de faturamento, nunca ocupou uma cadeira na diretoria da OCEPAR. Em terceiro lugar, a CAPAL, que ocupa o décimo quarto lugar do ranking, não fez parte de nenhuma diretoria desde 1996. Por último, quanto à regra de composição de parte da diretoria pelo núcleo regional, em relação ao Sudoeste, a COASUL é a única cooperativa deste núcleo que aparece no ranking da revista Exame, tendo ocupado uma cadeira na diretoria da OCEPAR nas últimas três gestões. Entendemos que esses pontos extremos dos nossos dados não alteram a tendência geral da forma de ocupação das diretorias da OCEPAR.
} 
e a experiência na ocupação de cargos, sua origem e suas características sociais. E, de outro, apontam para alguns aspectos das "vias" (Giddens, 1974) que devem ser percorridas por aqueles que dela fazem parte, seja em termos de atributos sociais e formação educacional, seja em termos de trajetória profissional e de carreira. Como vimos acima, a essas características podemos acrescentar o carisma eleitoral e político, dado que todos possuem a capacidade de obter o apoio eleitoral de seus pares e capacidade de exercer a representação política dos interesses das cooperativas.

\section{A atuação política da OCEPAR}

Embora a análise da ação política propriamente dita da OCEPAR ultrapasse os objetivos deste artigo e exija uma pesquisa específica e mais profunda, podemos acrescentar alguns comentários sobre os padrões de ação política desta entidade, dada a sua importância no processo da constituição e efetivação do cooperativismo agroindustrial enquanto ator político e por se tratar de tarefa de responsabilidade dos indivíduos resultantes do processo de recrutamento aqui analisado, a elite cooperativista.

Observando os pronunciamentos públicos e os relatórios de atividades da entidade, bem como as notícias veiculadas no seu informe diário, constatamos que o presidente, na maioria das vezes, é quem faz os pronunciamentos públicos e políticos do setor cooperativo paranaense, mas apenas enquanto porta-voz das posições tomadas pela diretoria. No âmbito estadual, há a menção a uma "frente parlamentar pelo cooperativismo", criada em 2012, por ocasião do ano internacional do cooperativismo, e que atuaria na Assembleia Legislativa do Paraná.

Em relação ao Congresso Nacional, o cooperativismo possui uma frente parlamentar própria, a Frente Parlamentar do Cooperativismo (FRENCOOP), constituída em 1986, e que conta com a presença de deputados paranaenses aliados à causa cooperativista. A FRENCOOP possui registros de atuação na Constituinte de 1986-1988, e seus resultados foram destacados pela OCB e atribuídos à ação conjunta desta frente com o Sistema OCB. Entre tais resultados estariam os artigos que incluíram o cooperativismo na Constituição Federal de $1988^{37}$.

Segundo a OCB, na legislatura de 2015-2018 do Congresso Nacional, a FRENCOOP teria congregado $47 \%$ destes parlamentares, sendo 245 deputados e 36 senadores, e 38,3\% dos líderes de partidos e de blocos de parlamentares. Tais parlamentares são destacados pela OCB como responsáveis por nortear "[...] a discussão e a votação de propostas" e "[...] acumulam uma série de atribuições importantes, ligadas à articulação política e ao trabalho de unificação do discurso partidário" (Organização das Cooperativas Brasileiras, 2015, p. 40). Isso é importante porque há indícios da relação entre OCEPAR e FRENCOOP, em especial com os deputados paranaenses que compõem a FRENCOOP.

A ação política direta na OCB, em cuja diretoria o presidente da OCEPAR ocupa uma cadeira, e na FRENCOOP, também é relevante. Constatamos que há menções a reuniões com deputados desta frente parlamentar nos informes da OCEPAR. Outro indicador interessante é o fato de o presidente da FRENCOOP, no período que estamos considerando, ter sido o deputado paranaense Osmar Serraglio (PMDB).

Considerando que a atividade econômica das cooperativas agroindustriais é a agropecuária, em uma dimensão industrial, os parlamentares que gravitam na FRENCOOP tendem a ser os mesmos que compõem a Frente Parlamentar da Agricultura. Entretanto, para certos assuntos,

\footnotetext{
${ }^{37}$ Artigos: $5^{\circ}$, XVIII; 146, III, alínea " $\mathrm{c}^{\prime \prime}, 174, \S 2^{\circ}$ e $\$ 4^{\circ}$, art. 186, VI, art. 192. Mais recentemente, esta frente atuou sobre os seguintes projetos: regulamentação do Ramo Crédito (Lei Complementar 130/2012) e o Ramo Trabalho (Lei n 12.690/2014), criação do Serviço Nacional de Aprendizagem do Cooperativismo (SESCOOP), através da Medida Provisória $n^{\circ} 1.715 / 98$, e o que estabeleceu o novo Código Florestal (Lei n 12.651/2012) (Organização das Cooperativas Brasileiras, 2015, p. 3).
} 
esta frente tem se mostrado mais atuante. Seja como for, a atuação da elite cooperativista que estudamos continua sendo importante, dado que as decisões tomadas e os posicionamentos são acordados com os representantes da agropecuária, o que inclui as cooperativas empresariais.

Quanto à atuação política da OCEPAR junto ao Poder Executivo estadual, podemos notar o teor das notícias diárias do informe da entidade, Paraná Cooperativo, voltadas principalmente para questões tributárias, como o ICMS, de infraestrutura (porto e estradas) e ligadas à agropecuária. Além disso, a OCEPAR também faz parte de um bloco informal, o G7, composto pelos presidentes das entidades paranaenses de representação empresarial. Este grupo informal de entidades já foi identificado como $G 8$ e se reúne para tratar de assuntos relacionados ao setor produtivo paranaense junto ao Governo do Paraná. Em geral, é composto pelas seguintes entidades: OCEPAR, Federação do Comércio do Paraná, Federação da Agricultura do Estado do Paraná, Federação das Indústrias do Estado do Paraná, Federação das Associações Comerciais e Empresariais do Estado do Paraná, Federação das Empresas de Transporte de Cargas do Estado do Paraná e Associação Comercial do Paraná. Inclusive, em junho de 2018, a coordenação do G7 foi assumida pelo atual presidente do Sistema Ocepar, José Roberto Ricken, que no seu discurso de posse afirmou que este grupo é "[...] o instrumento de representação e integração dos empresários paranaenses nos planos de desenvolvimento do Paraná e de diálogo com o governo estadual", e que "[...] vivemos um momento de crise política. Obviamente isso é assunto de discussão interna do grupo, independentemente de partido ou de tendência política, afinal a preocupação é com a viabilidade do sistema político brasileiro" (Sindicato e Organização das Cooperativas do Estado do Paraná (2018). Ainda em relação ao Poder Executivo federal, verificamos também a ocorrência de várias reuniões da OCEPAR com autoridades deste poder ${ }^{38}$.

Deste breve relato, podemos destacar, em primeiro lugar, a importância política da elite cooperativista que dirige a OCEPAR, em relação ao Executivo e o Legislativo, tanto no nível estadual quanto no federal. Além disso, constatamos a ocorrência e a importância das articulações entre esta elite cooperativista e outras elites políticas, tais como a elite empresarial e a elite parlamentar. Por fim, podemos destacar a relevância e a intensidade do vínculo do cooperativismo agroindustrial e da elite cooperativista com as questões políticas do meio empresarial em geral.

\section{Considerações finais}

A Sociologia Política aqui adotada para estudar a constituição do cooperativismo agroindustrial enquanto ator político remeteu à importância da análise dos condicionantes tanto institucionais quanto sociais do recrutamento da elite cooperativista. Além disso, podemos enfatizar novamente a importância de estudos sobre a relação entre grandes cooperativas e a política, dado que esta relação com outros tipos de cooperativismo já foi explorada ${ }^{39}$.

Verificamos que, ao lado da relevância econômica das grandes cooperativas empresariais, ocorre, de forma não menos importante, a sua relevância política. Assim, além dos complexos desafios gerenciais relativos a esses grandes empreendimentos econômicos e do seu relevante papel na economia local e nacional, em particular aquele predominantemente agroindustrial, no qual o Paraná se destaca, colocam-se para o cooperativismo agroindustrial e para a elite

\footnotetext{
${ }^{38} \mathrm{Em} 2017$, os destaques foram a mobilização em torno do Plano Agrícola, bastante criticado pela entidade, e do FUNRURAL, que culminou no parcelamento das dívidas através da Medida Provisória n 793/2017 e da Lei n 13.606/2018.

${ }^{39}$ Podemos mencionar a análise de Regina Bruno (2016) sobre a exclusão de parte dos agricultores familiares das cooperativas agroindustriais, que embora não seja objeto da nossa análise, chama a atenção para os efeitos da ação política dos dirigentes de cooperativas. Há também o trabalho de Wilder Robles (2019) sobre o MST. A respeito de nossos objetivos, temos os trabalhos de Costa \& Stöberl (2016) e de Paulo Stöberl (2019).
} 
cooperativista complexas questões políticas. Tais questões vão desde o processo de eleição enquanto dirigentes das cooperativas, passando pelo recrutamento para a direção da entidade de representação política, até a atuação desta junto às autoridades e instituições políticas na defesa dos interesses dos cooperados, em âmbito estadual e nacional. Isso ganha ainda mais importância quando se considera o contexto democrático, ou seja, o funcionamento da democracia no Brasil e a natureza consultiva e eletiva do processo de recrutamento das elites políticas.

Embora não tenhamos nos debruçado sobre a ação política desta entidade, a relevância do protagonismo político da OCEPAR e da elite cooperativista aqui analisada, no âmbito estadual e no sistema de representação nacional do cooperativismo, mostra que os presidentes das grandes cooperativas agroindustriais, através da diretoria da OCEPAR, são os agentes fundamentais deste protagonismo e decisivos no processo de constituição do cooperativismo agroindustrial enquanto ator político.

Além disso, os membros da elite cooperativista, assim como os CEOs das grandes empresas, devem apresentar o conhecimento do negócio, mas devem também ser cooperados, isto é, membros da sociedade e atuantes na agricultura, com propriedade produtiva que opere com a cooperativa, além de possuírem carisma eleitoral e político, suficiente para alcançarem tal posição, ainda que no âmbito de uma assembleia de pares. Em suma, os presidentes evidenciam uma característica importante da elite cooperativista, mais uma vez, a combinação de traços do que aqui consideramos de elite econômica e elite empresarial.

Convém ressaltar a impossibilidade sociológica de estabelecer uma correlação imediata de causa e efeito entre a ocupação da diretoria e poder efetivo na entidade ou o sucesso no jogo político. Por mais que seja relevante, essa correlação só serve como hipótese de trabalho a ser testada, e não simplesmente pressuposta, mesmo quando existem indícios fortes neste sentido. Entretanto, tal hipótese ganha força a partir dos achados aqui apresentados.

Vimos também a necessidade do desenvolvimento de categorias analíticas que deem conta das particularidades do fenômeno do cooperativismo empresariale de sua constituição enquanto ator político, a despeito de algumas semelhanças com, de um lado, as empresas, e, de outro, os grupos de interesse e as entidades de representação política empresarial. Entretanto, as semelhanças em nada reduzem a importância das diferenças e especificidades, bem como das questões clássicas da análise sociológica relacionada à ação política de um dado grupo social, por exemplo, a lógica da ação coletiva, a organização, o processo de representação política de grupo, a capacidade de influência ou poder político, a constituição de uma elite, a relação com a sociedade etc., as quais certamente muito têm a contribuir com a compreensão daquelas particularidades.

Daí a necessidade de profundar o diálogo com a literatura tanto sobre o cooperativismo, quanto sobre os empresários, se possível em perspectiva comparada com outros setores, estados e países. Além disso, verificamos a impossibilidade de categorização dos dirigentes de cooperativas como patronato rural ou empresariado, dado que, por um lado, se trata de uma figura administrativa e jurídica distinta da empresa privada ou sociedade empresária, e por outro, de um setor econômico distinto da agricultura e da indústria, mesmo que guarde relações com ambas. Isso impacta sobre o processo de sua constituição enquanto ator político, pois suas formas institucionais de representação são próprias e distintas de outras que são mais ou menos reguladas pelo Estado. Nem por isso as grandes cooperativas e a sua entidade deixaram de ter articulações intensas com os setores empresariais e suas entidades de representação política ${ }^{40}$.

Por sua vez, a análise do processo institucional de seleção e recrutamento para a diretoria da OCEPAR, no qual o indivíduo deve ser cooperado e dirigente de uma cooperativa e passar

${ }^{40}$ Sobre esse ponto, ver Costa \& Stöberl (2016). 
por eleição ou indicação na região de sua cooperativa para figurar na chapa de eleição, indica a existência de um complexo processo de articulação de demandas de diversos setores, inclusive para além do agroindustrial, mesmo que este ocupe uma posição majoritária na entidade no período aqui estudado, dado que a unidade estabelecida pela lei das cooperativas ou mesmo as particularidades do formato institucional da entidade não impedem eventuais conflitos entre as cooperativas em função de suas naturezas diversas.

Podemos destacar também a importância tanto dos aspectos estatutários, portanto, do formato institucional, quanto da disposição dos principais dirigentes das cooperativas em construir uma forma harmoniosa, acordada e convergente, e anterior ao processo formal de eleição de definição das diretorias, no caso, as assembleias, além de outras medidas organizacionais de grande relevância, como a profissionalização da presidência, aspecto exclusivo e inexistente em entidades de representação de grupos sociais ou econômicos. Esse processo contempla até mesmo outros setores, como saúde e crédito, o que indica que este aspecto institucional, decisivo para o recrutamento, ultrapassa as questões do setor agroindustrial. Como dissemos acima, não estamos supondo que não existam conflitos, naturais em qualquer coletivo, mas apenas constatando que esses vêm sendo resolvidos e absorvidos pelo processo de recrutamento e pelo formato institucional subjacente.

Esses aspectos são fundamentais porque remetem às formas como este ator econômico, com todas as suas particularidades, enfrenta e resolve as questões relacionadas não apenas às atividades empresariais correlatas, mas sobretudo o enfretamento do processo, institucionalizado em maior ou menor grau, de sua constituição enquanto ator político, no qual conflitos e diferenças têm que ser administradas e encaminhadas internamente para depois poderem ser articuladas externamente. Isso tem forte impacto não apenas na definição dos padrões de ação política deste grupo e de suas relações com a política, mas também de seu próprio funcionamento e desenvolvimento enquanto empreendimento econômico. Este processo remete a um aprendizado que tanto os indivíduos quanto os grupos e suas instituições passam, em especial nas sociedades democráticas. Daí a sua grande relevância no estudo não apenas do próprio ator, como também do regime político e até mesmo da cultura política da democracia em funcionamento no Brasil.

Por fim, podemos ressaltar algumas contribuições para a construção de futuras agendas de pesquisa sobre o objeto que aqui estudamos. Em primeiro lugar, a grande homogeneidade de trajetória e social dos membros desta elite cooperativista sugere a necessidade de aprofundar a caracterização desta homogeneidade, a partir, por exemplo, dos critérios propostos por Suzanne Keller (Keller, 1967) acima mencionados, bem como testar a hipótese de que, no processo de recrutamento, também há um alto grau de coesão, ou seja, de proximidade na forma de pensar e se posicionar frente às questões administrativas e às político-ideológicas, e principalmente como isso se articula com suas ações enquanto dirigentes das cooperativas e de sua entidade de representação ${ }^{41}$. Articulada a esta frente, seria interessante produzir uma prosopografia dos presidentes da OCEPAR ${ }^{42}$.

Em segundo lugar, constatamos a necessidade de uma pesquisa aprofundada sobre a ação política da OCEPAR frente aos poderes Executivo e Legislativo, no âmbito estadual e federal, dada a importância política que tais dirigentes podem adquirir no cenário político eleitoral, em especial em âmbito local, e nesse processo a sua articulação com entidades de representação empresarial, tais como as associações e federações patronais, bem como as relações com os sindicatos para

${ }^{41}$ Sobre este aspecto, Paulo Stöberl (2019) verificou que há um tipo ideal (Weber) de membro da elite cooperativista: homens brancos, brasileiros, de meia-idade, com longas carreira únicas e que atuam politicamente tendo por base uma orientação movida por uma mentalidade de ator econômico. Além disso, possuem grande aderência à democracia, são partidários da livre economia e da redução do Estado como forma de valorizar o empreendedorismo.

${ }^{42}$ Em relação a esse aspecto, podemos citar as proposições de Heinz \& Codato (2015). 
tratar de questões trabalhistas. Todas essas questões fazem parte da realidade das cooperativas e impactam profundamente o seu funcionamento e a realização de seus objetivos, portanto, relevantes até mesmo para as abordagens teóricas e doutrinárias sobre o cooperativismo.

Quanto aos conflitos, sejam internos ao cooperativismo empresarial, sejam no que tange aos embates externos, em âmbito nacional e estadual, por um lado, poderíamos fazer um contraste com a homogeneidade acima mencionada. E, por outro, poderíamos acrescentar um estudo das estratégias de ação, ou padrões de ação política, e a questão clássica nos estudos de ação política, que é a eficácia ou força política dos atores. Seja como for, nossa pesquisa mostrou que um dos aspectos institucionais importantes da constituição do cooperativismo empresarial enquanto ator político é exatamente a forma de administrar os conflitos, dado que nossa pesquisa não detectou sua ocorrência, ao contrário, constatou sinais institucionais de construção de consensos, o que obviamente não significa a eliminação de divergências.

Em suma, isso tudo remete ao nosso objetivo fundamental de contribuir para o desenvolvimento da questão acima colocada sobre a necessidade de criar categorias analíticas que tenham eficácia explicativa sobre o objeto aqui contemplado, beneficiando-se do debate com os estudos já disponíveis sobre fenômenos semelhantes e correlatos e abrindo espaço para novas pesquisas empíricas, e de chamar a atenção para a importância da dimensão política das grandes cooperativas e para a compreensão, deste ponto de vista, de sua história, de seu funcionamento enquanto empreendimento econômico de grande complexidade administrativa e relevância econômica, bem como para as suas perspectivas futuras.

Isso poderá trazer grandes contribuições para a compreensão deste fenômeno, que tem importantes implicações sociais, econômicas e políticas, a qual se mostra decisiva para se pensar o próprio funcionamento das grandes cooperativas empresariais e das eventuais políticas públicas a elas correlatas. Assim, o estudo de um segmento do cooperativismo empresarial sugere a força e a complexidade das formas associativas que pulsam na sociedade brasileira e 0 quanto é importante analisar o seu impacto sobre o funcionamento não só sobre a economia e a sociedade, mas também sobre o futuro da democracia no país, dada a relevância das formas organizadas da sociedade para a estabilidade e a qualidade dos regimes políticos democráticos.

\section{Referências}

Binotto, E., Nakayama, M. K., \& Siqueira, E. S. (2013). A criação de conhecimento para a gestão de propriedades rurais no Brasil e na Austrália. Revista de Economia e Sociologia Rural, 51(4), 681-698. http://dx.doi.org/10.1590/S0103-20032013000400004

Bresser-Pereira, L. C. (1974). Empresários e administradores no Brasil. Brasiliense.

Bruno, R. (2016). Desigualdade, agronegócio, agricultura familiar no Brasil. Revista Estudos Sociedade e Agricultura, 24(1).

Cardoso, F. H. (1964). Empresário industrial e desenvolvimento econômico no Brasil. Difel.

Codato, A. N. (2015). Metodologias para a identificação de elites: três exemplos clássicos. In A. N. Codato \& R. M. Perissinotto (Eds.), Como estudar elites. Editora UFPR.

Codato, A., \& Perissinotto, R. M. (2011). Por uma análise societalista da política. Editora UFPR. Codato, A., \& Perissinotto, R. M. (2015). Como estudar elites. Editora UFPR.

Codato, A., Costa, L. D., Massimo, L., \& Heinz, F. (2016). Regime político e recrutamento parlamentar: um retrato coletivo dos senadores brasileiros antes e depois da ditadura. Revista de Sociologia e Politica, 24(60), 47-68. http://dx.doi.org/10.1590/1678-987316246005 
Coradini, O. L. (2006). Representação profissional e elites políticas no Brasil no período recente. Política \& Sociedade, 9. http://dx.doi.org/10.5007/\%25x

Costa, D. R. M., Chaddad, F. R., \& Azevedo, P. F. (2012b). Separação entre propriedade e decisão de gestão nas cooperativas agropecuárias brasileiras. Revista de Economia e Sociologia Rural, 50(2), 285-300. http://dx.doi.org/10.1590/S0103-20032012000200005

Costa, D. R. M., Azevedo, P. F., \& Chaddad, F. R. (2012a). Determinantes da separação entre propriedade e gestão nas cooperativas agropecuárias brasileiras. Revista $A D M, 47(4), 581$ 595. https://doi.org/10.5700/rausp1060

Costa, P. R. N. (2005). Empresariado, regime político e democracia: Brasil, anos de 1990. Revista Brasileira de Ciências Sociais, 20(57), 109-207. http://dx.doi.org/10.1590/S010269092005000100007

Costa, P. R. N. (2014). Elite empresarial e elite econômica: o estudo dos empresários. Revista de Sociologia e Política, 22 (52), 47-57. https://doi.org/10.1590/1678-987314225204

Costa, P. R. N., \& Borck, I. S. S. F. (2019). Empresariado, parlamento e democracia: a CNI e o Congresso Nacional (2010-2017). Opinião Pública, 25(2), 433-471. http://dx.doi. org/10.1590/1807-01912019252433

Costa, P. R. N., \& Stöberl, P. R. (2016). Cooperativas e representação política empresarial no Brasil: o caso do cooperativismo rural no Paraná. Política \& Sociedade, 15(32), 258. http:// dx.doi.org/10.5007/2175-7984.2016v15n32p258

Crúzio, H. O. (1999). Por que as cooperativas agropecuárias e agroindustriais brasileiras estão falindo? Revista de Administração de Empresas, 39(2), 18-26. http://dx.doi.org/10.1590/ S0034-75901999000200003

Dahl, R. A. (1961). Who governs? Democracy and power in an American city. Yale University Press.

Ensslin, S. R., Ensslin, L., Imlau, J. M., \& Chaves, L. C. (2014). Processo de mapeamento das publicações científicas de um tema: portfólio bibliográfico e análise bibliométrica sobre avaliação de desempenho de cooperativas de produção agropecuária. Revista de Economia e Sociologia Rural, 52(3), 587-608. http://dx.doi.org/10.1590/S0103-20032014000300010

Franke, W. (1973). Direito das sociedades cooperativas. Saraiva.

Gaxie, D. (2012). As lógicas do recrutamento político. Revista Brasileira de Ciência Política, 8(8), 165-208. http://dx.doi.org/10.1590/S0103-33522012000200007

Giddens, A. (1974). Elites in the British Class Structure. In A. Stanworth \& P. Giddens (Eds.), Elites and power in British Society. Cambridge University Press.

Gide, C. (1955). Compendio d'Economia Política. Globo.

Gide, C., \& Rist, C. (1949). Historia de las Doctrinas Económicas. Depalma.

Gomes, A. M. C. (1979). Burguesia e trabalho: política e legislação social no Brasil 1917-1937. Campus.

Grynszpan, M. (1999). Ciência política e trajetórias sociais: uma sociologia histórica da teoria das elites. FGV.

Heinz, F., \& Codato, A. N. (2015). A prosopografia explicada para cientistas políticos. In R. M. Codato \& A. Perissinotto (Eds.), Como estudar elites. Editora UFPR.

Ilha, P. C. S., Piacenti, C. A., \& Leismann, E. L. (2018). Uma Análise Comparativa da Competitividade Econômico-financeira das Cooperativas Agroindustriais do Oeste do Paraná. Revista de Economia e Sociologia Rural, 56(1), 91-106. http://dx.doi.org/10.1590/1234-5678180694790560106 
Immergut, E. M. (1998). The theoretical core of the New Institutionalism. Politics \& Society, 26(1), 5-34. http://dx.doi.org/10.1177/0032329298026001002

Instituto Paranaense de Desenvolvimento Econômico e Social - IPARDES. Secretaria de Estado do Planejamento e Coordenação Geral. (1974). Cooperativas de produção agropecuária do Estado do Paraná: diagnóstico e análises. Curitiba.

Keller, S. (1967). O destino das Elites. Forense.

Leite, M. P., \& Duaibs, R. (2017). Cooperatives and productive internationalization: a new challenge. Sociologia \& Antropologia, 7(2), 521-543. http://dx.doi.org/10.1590/2238-38752017v728

Leopoldi, M. A. P. (2000). Política e interesses: as associações industriais, a política econômica e o Estado na industrialização brasileira. Paz e Terra.

Mancuso, W. P. (2007a). O empresariado como ator político no Brasil: balanço da literatura e agenda de pesquisa. Revista de Sociologia e Politica, (28), 131-146. http://dx.doi.org/10.1590/ S0104-44782007000100009

Mancuso, W. P. (2007b). O Lobby da Indústria no Congresso Nacional. EDUSP/HUMANITAS/FAPESP.

March, J. G., \& Olsen, J. P. (2008). Neo-institucionalismo: fatores organizacionais na vida política. Revista de Sociologia e Politica, 16(31), 121-142. http://dx.doi.org/10.1590/S010444782008000200010

Martins, L. (1968). Industrialização, burguesia nacional e desenvolvimento. Saga.

Mendonça, S. R. (2002). A Política de cooperativização agrícola do Estado brasileiro (1910-1945). Editora da Universidade Federal Fluminense.

Mendonça, S. R. (2010). Patronato rural no Brasil recente (1964-1993). Editora da UFRJ.

Michels, R. (1982). Sociologia dos partidos políticos. UnB.

Mills, C. W. (1981). A elite do poder. Zahar.

Moreira, V. R., Silva, C. L., Moraes, E. A., \& Protil, R. M. (2012). O cooperativismo e a gestão dos riscos de mercado: análise da fronteira de eficiência do agronegócio paranaense. Revista de Economia e Sociologia Rural, 5a(1), 51-68. http://dx.doi.org/10.1590/S0103-20032012000100003

Mosca, G. (1992). La clase política. Fondo de Cultura Económica.

Olson, N. (1999). A lógica da ação coletiva. EDUSP.

Organização das Cooperativas Brasileiras - OCB. (2015). Panorama FRENCOOP: 55a Legislatura (2015-2018). Recuperado em 27 de junho de 2017, de http://www.brasilcooperativo.coop. br/site/ocb_congresso/downloads/panorama-frencoop-2015.pdf

Pareto, V. (1966). As elites e o uso da força na sociedade. In Sociologia Política. Zahar.

Perissinotto, R. M. (2004). Política e sociedade: por uma volta à Sociologia Política. Política e Sociedade, 3(5), 203-232.

Poulantzas, N. (1977). Poder político e classes sociais. Martins Fontes.

Putnam, R. (1996). Comunidade e democracia: a experiência da Itália moderna. Fundação Getúlio Vargas.

Robles, W. (2019). The politics of agricultural cooperativism in Brazil: a case study of the landless rural worker movement (MST). Journal of Co-Operative Organization and Management, 7(1), 10-25. http://dx.doi.org/10.1016/j.jcom.2019.02.001

Rodrigues, R. L., \& Guilhoto, J. J. M. (2004). Estrutura produtiva, relações intersetoriais e cooperativas agropecuárias no Paraná em 1980 e 1985. Revista de Economia e Sociologia Rural, 42(2), 243-266. http://dx.doi.org/10.1590/\$0103-20032004000200004 
Setti, E. O. (2011). Cooperativismo Paranaense: Ocepar - 40 anos construindo o futuro. Curitiba: OCEPAR.

Simioni, F. J., Siqueira, E. S., Binotto, E., Spers, E. E., \& Araújo, Z. A. S. (2009). Lealdade e oportunismo nas cooperativas: desafios e mudanças na gestão. Revista de Economia e Sociologia Rural, 47(3), 739-765. http://dx.doi.org/10.1590/S0103-20032009000300010

Sindicato e Organização das Cooperativas do Estado do Paraná - OCEPAR. (2015). Relatório de atividades e prestação de contas - 2014. Curitiba.

Sindicato e Organização das Cooperativas do Estado do Paraná - OCEPAR. (2016). Relatório de atividades e prestação de contas - 2015. Curitiba.

Sindicato e Organização das Cooperativas do Estado do Paraná - OCEPAR. (2017). Somos o cooperativismo no Paraná. Curitiba. Recuperado em 5 de novembro de 2018, de http:// www.paranacooperativo.coop.br/ppc/images/Comunicacao/2018/publicacoes/folder_ cooperativismo_pr_web.pdf

Sindicato e Organização das Cooperativas do Estado do Paraná - OCEPAR. (2018). O G7 muda de coordenação. Curitiba. Recuperado em 27 de junho de 2018, de http://www.paranacooperativo. coop.br/ppc/index.php/sistema-ocepar/comunicacao/2011-12-07-11-06-29/ultimasnoticias/118286-g7

Sindicato e Organização das Cooperativas do Estado do Paraná - OCEPAR. (2019a). Valor 1000: cooperativas do $P R$ sobem posições no ranking das maiores empresas do país. Recuperado em 23 de agosto de 2019, de http://www.paranacooperativo.coop.br/ppc/index.php/ sistema-ocepar/comunicacao/2011-12-07-11-06-29/ultimas-noticias/123951-valor-1000cooperativas-do-pr-sobem-posicoes-no-ranking-das-maiores-empresas-do-pais

Sindicato e Organização das Cooperativas do Estado do Paraná - OCEPAR. (2019b). Ranking Exame: Cooperativas paranaenses se destacam entre as 1000 Maiores Empresas do Brasil. Recuperado em 23 de agosto de 2019, de http://www.paranacooperativo.coop.br/PPC/index. php/sistema-ocepar/comunicacao/2011-12-07-11-06-29/ultimas-noticias/119201-rankingexame-cooperativas-paranaenses-se-destacam-entre-as-1000-maiores-empresas-do-brasil

Stöberl, P. R. (2018). Conceito de sociedade cooperativa. In A. A. Gonçalvez Neto (Ed.), Sociedades cooperativas. Lex.

Stöberl, P. R. (2019). A perspectiva política da elite econômica-representativa do cooperativismo agroindustrial. Universidade Federal do Paraná.

Szwako, J., Moura, R., \& D'Avila Filho, P. (Eds.). (2016). Estado e sociedade no Brasil: a obra de Renato Boschi e Eli Diniz. Rio de Janeiro: CNPq, FAPERJ, INCT/PPED, Ideia D.

Valarini, E., \& Pohlmann, M. (2013). Elite economica no Brasil: discussões acerca da internacionalizacao da carreira de executivos Brasileiros. Revista de Sociologia e Politica, 21(47), 39-53. http://dx.doi.org/10.1590/S0104-44782013000300005

Weber, M. (1991). Economia e sociedade. UnB.

Weber, M. (1993). Ciência e política: duas vocações. Cultrix.

Weber, M. (2015). Política como vocação. Martin Claret. 